This PDF is a selection from an out-of-print volume from the National Bureau of Economic Research

Volume Title: Inflation, Tax Rules, and Capital Formation

Volume Author/Editor: Martin Feldstein

Volume Publisher: University of Chicago Press

Volume ISBN: 0-226-24085-1

Volume URL: http://www.nber.org/books/feld83-1

Publication Date: 1983

Chapter Title: Inflation, Tax Rules, and the Accumulation of Residential and Nonresidential Capital

Chapter Author: Martin Feldstein

Chapter URL: http://www.nber.org/chapters/c11331

Chapter pages in book: (p. 81 - 100) 


\section{Inflation, Tax Rules, and the Accumulation of Residential and Nonresidential Capital}

For nearly two decades, the United States has pursued a series of shortrun policies that have increased the rate of inflation and sustained it at a high level. The rate of increase of the general price level (as measured by the GNP deflator) rose from less than 2 percent a year in the early 1960 s to more than 8 percent a year in the late 1970s. The expansionary monetary and fiscal policies began in the early 1960 s as an attempt to lower the unemployment rate and expand the level of output. Easy money, lower tax rates on capital income, and specific incentives for business investment were combined with the aim of stimulating investment and thereby, through the traditional multiplier process, reducing unemployment. Although the rate of inflation began to rise, many economists argued that "moving up the Phillips curve" to higher inflation and lower unemployment represented a desirable trade off. Then came the decision by President Johnson to expand both the Vietnam war and his Great Society programs. He insisted on doing so without a tax increase but with an easy money policy aimed at keeping interest rates from rising. This moved the inflation rate up sharply, to more than 5 percent as the 1970s began.

In the 1970 s, inflationary monetary and fiscal policies continued to be pursued despite a lack of agreement on the rationale for those policies even among the prevailing economists of that decade. In effect, these economists and the politicians agreed on the treatment of the economy even though they disagreed about the proper diagnosis of its economic condition. First, there were those who continued to believe in a long-run

Reprinted by permission from Scandinavian Journal of Economics 84 (June 1980): 636-50.

This paper is part of the NBER study of capital formation. I am grateful to my colleagues at the NBER for numerous discussions of this subject and for comments on an earlier draft. 
Phillips curve trade-off between inflation and unemployment. They advocated expansionary policy in the hope of reducing unemployment permanently even if that meant accepting a higher inflation rate. Second, there were those who recognized that no long-run trade-off exists but who misjudged how high the noninflationary unemployment rate had become because of changes in the demographic structure of the labor force and in the transfer programs that encouraged higher unemployment. They advocated expansionary monetary and fiscal policies because they believed that the economy was still operating with "too much unemployment." Finally, there were those who correctly perceived that the economy was at or below the noninflationary unemployment rate but who resisted a tightening of monetary and fiscal policy because they were unwilling to pay the price in higher unemployment for slowing the rise in inflation or reducing its level.

In this way the economy drifted to higher and higher rates of inflation. ${ }^{1}$ Although some of the year-to-year changes in inflation were unexpected, the general level and even some of the upward drift clearly came to be anticipated. For more than a decade now, a major debate among American macroeconomists has been about whether such anticipated inflation has any effects on the real economy. At least since Milton Friedman's (1968) presidential address, economists have recognized that expected inflation is perfectly neutral in a simplified economy with flexible prices, inelastic money demand, and no taxes. Subsequent research by Barro (1977) Lucas (1972), Sargent and Wallace (1975), and others has refined this idea and emphasized the corresponding neutrality of expected changes in the stock of money. ${ }^{2}$

The important question, however, is whether the neutrality of anticipated changes in money and in the price level are relevant to the actual economy in which we live. James Tobin (1965) emphasized that even fully anticipated inflation is not neutral because the demand for money balances varies inversely with the nominal interest rate and therefore with the expected rate of inflation. An increase in inflation caused by a more rapid growth of money would therefore raise the capital intensity of the economy by inducing households to substitute real capital for money in their portfolios. Stanley Fischer $(1979 b)$ has recently examined the lead and lag patterns by which expected changes in the money stock can alter the capital stock and real output through the Tobin money-capital substitution effect. Although this portfolio substitution process is analytically correct, it is generally agreed that the magnitude of the Tobin effect is extremely small. ${ }^{3}$

1. The OPEC price shocks played a significant part in this process but do not alter the basic story that I have told above. For more extensive accounts, see Blinder (1979), Eckstein (1978), Feldstein (1981c), and Gordon (1981).

2. See also the papers and discussion in Fischer $(1979 a)$.

3. See sec. 6.1, especially sec. 6.1 .5 , for a discussion of why the Tobin effect is empirically too small to matter. 
By contrast, the interaction of inflation and the tax rules can have very substantial effects on the incentive to save and on the relative returns to different types of investments. In Feldstein (1976; chap. 3) I examined the way in which the tax-inflation interaction could lower total capital formation by reducing the incentive to save. Then in Feldstein (1980; chap. 5) I showed how the tax-inflation interaction would encourage individual investors to substitute interest-bearing government debt for real capital in their portfolios and thereby reduce the real capital intensity of the economy. The present paper extends this analysis to examine how inflation diverts capital from plant and equipment to owner-occupied housing. ${ }^{4}$

The tax burden on business capital rises when there is inflation. Under existing U.S. tax rules, ${ }^{5}$ inflation affects the taxation of business capital in three important ways. First, because of the "historic cost" approach to calculating the cost of production, a higher rate of inflation reduces the real value of depreciation allowances and understates the cost of replacing the goods withdrawn from inventory. Second, the owners of the equity of business firms pay capital gains tax on the rise in the nominal value of the capital stock. And, third, the firm gets to deduct nominal interest payments (thereby understating its taxable profits) but the creditors must pay tax on nominal interest receipts (thereby overstating their taxable income). Since the effective tax rate on the reduced corporate income is very close to the effective tax rate on the increased creditor income (Feldstein and Summers, 1979), this third effect is very small. On balance, inflation therefore raises the tax burden on the income from business investment.

Under present U.S. tax law, an individual who owns his own house may deduct the nominal interest payment in calculating taxable income and does not pay tax on the implicit rental income provided (in kind) by his house. In addition, the capital gains on owner-occupied housing are virtually untaxed.

Since the stock of housing capital is about 74 percent of the stock of nonresidential capital, ${ }^{6}$ an incentive to shift capital from plant and equipment to housing can have a significant effect on the amount of plant and equipment in the economy. The ratio of net investment in residential capital to net investment in plant and equipment rose from 52 percent in the last half of the 1960 s to 76 percent in the last half of the 1970 s. In

4. I have previously discussed the way that inflation and tax rules combine to achieve this distortion in Feldstein $(1980 a, b)$ but have not previously presented a formal model. For other analyses of the way that the tax-inflation interaction affects the demand for residential capital, see Hendershott $(1979,1980)$, Hendershott and Hu (1979), Hendershott and Shilling (1980), Poterba (1980), and Summers (1981).

5. I.e., the tax rules as of July 1981 .

6. This excludes land and includes inventories as well as fixed capital. Owner-occupled housing accounts for $\mathbf{4 2}$ percent of fixed capital alone. The data on capital stocks and inventories are from the Federal Reserve Board's Balance Sheets of the U.S. Economy. 
Feldstein (1980e; chap. 14 below), I presented econometric evidence that the interaction of tax rules and inflation reduced the incentive to invest in plant and equipment and that this can explain most of the variation in the share of GNP devoted to such investment during the past three decades.

The present paper analyzes the effect of the interaction between tax rules and inflation on the size and allocation of the capital stock with particular emphasis on the role of owner-occupied housing. The analysis is developed in the framework of an economy that is in equilibrium and in which a constant fraction of disposable income is saved. In this model, I show that, with current U.S. tax laws, an increase in the rate of inflation reduces the equilibrium amount of business capital employed in the economy and raises the amount of housing capital. The analysis also shows that a higher rate of inflation lowers the real net-of-tax rate of return to the provider of business capital. In a richer model than the current one, that is, in a model in which the rate of personal saving was an increasing function of the net rate of return, a higher inflation rate would the refore lower the rate of saving.

The present analysis also shows that permitting firms to depreciate investments more rapidly for tax purposes increases the accumulations of business capital but that, unless firms are permitted to expense all investment immediately, an increase in inflation continues to depress the accumulation of business capital.

The model considered in this paper is a very simple one. I ignore several issues that $I$ have considered in earlier papers: changes in the saving rate, changes in the demand for money, government debt, and the mixture of debt and equity in corporate finance. ${ }^{7}$ A model cannot be a complete picture of reality but should help to elucidate some particular aspect of reality.

One final point should be emphasized before turning to the formal analysis. Because the relation between inflation and capital formation depends on the fiscal structure of the economy, the specific distorting effect of inflation is not a universal constant but differs among countries and even within the same country from time to time.

\subsection{A Growing Economy with Inflation and Housing}

The simplest framework within which to examine the effect of inflation on the composition of the capital stock is an economy with two sectors. The corporate business sector produces a general good that can be used for both consumption and investment. The unincorporated household sector produces the services of the owner-occupied housing stock. The population grows exogenously in this economy at a constant rate $(n)$ and the labor force is a fixed fraction of the population. Labor is employed

7. See Feldstein (1976, chap. 3 above; 1980) and Feldstein, Green, and Sheshinski (1978). 
only in the production of the general good; housing services are proportional to the stock of housing and are produced without labor. ${ }^{8}$

\subsubsection{The Business Sector}

If the general good is produced with constant returns to scale, the technology can be described by a production function that relates output per employee $(y)$ to the capital stock per employee used in this sector $(k)$ :

$$
y=f(k)
$$

For simplicity, output is measured net of depreciation and all technical progress is ignored.

The pretax rate of return on corporate capital is $f^{\prime}$. In the absence of inflation, corporations pay tax at rate $\tau$ on this return to capital. The net-of-tax returns on the marginal investment, $(1-\tau) f^{\prime}$, must in equilibrium be equal to the firms' net cost of funds. The analysis is greatly simplified by assuming that all marginal investments are financed by debt. ${ }^{9}$ On these funds, firms pay interest rate $i$. Since interest expenses are deducted in calculating a firm's taxable income, the net cost of borrowed funds is $(1-\tau) i$ and the firm's equilibrium condition is $(1-\tau) f^{\prime}=(1-$ $\tau) i$ or just $f^{\prime}=i$.

If there is inflation and the price level rises at a constant rate, $\pi$, the nominal pretax rate of return on capital is $f^{\prime}+\pi$. If inflation did not alter the measurement of real taxable profits, the tax liability per unit of capital (ignoring for a moment the tax treatment of debt) would be $\tau f^{\prime}$ and the resulting nominal after-tax rate of return would be $(1-\tau) f^{\prime}+\pi$. In fact, with the tax accounting rules that have prevailed in the United States, inflation causes taxable profits to increase relative to real profits. Both historic cost depreciation and the use of FIFO inventory accounting cause an understatement of the true cost of production and therefore an overstatement of taxable profits. ${ }^{10}$ As an approximation, the increase in tax-

8. The model also ignores the land used in housing. In the current framework, inflation would raise the relative price of land.

9. The rationale for all "debt at the margin" finance is developed in Stiglitz (1973) and a model of growth equilibrium with such finance is presented in Feldstein (1976). More realistically, the costs of debt and equity funds depend on a firm's debt-equity ratio; see Gordon and Malkiel (1981) and Feldstein, Green, and Sheshinski (1978, chap. 4 above; 1979). It is worth noting that the analysis of this paper could be done equally easily for an economy without any debt finance. In such an economy, firms would use only equity finance and homeowners would have no mortgages. The same basic results about the allocation of capital would be obtained, indicating that the fundamental issue is the inflation-induced rise in the relative taxation of business income and not the deductibility of nominal interest payments on mortgages.

10. If depreciation schedules permit tax depreciation that is faster than economic depreciation, taxable profits in the absence of inflation will be less than true profits. The increase in real taxable profits caused by inflation may leave taxable profits greater or less than true profits. What matters is the change in the size of this difference, i.e., profits relative to real profits, and not the sign of the difference. 
able income per unit of capital can be written as a constant multiple of the inflation rate, $\lambda \pi$, per unit of capital." The additional tax is thus $\tau \lambda \pi$. The nominal rate of return to the corporation net of tax is therefore $(1-\tau) f^{\prime}$ $+\pi-\tau \lambda \pi$.

Since the nominal interest rate is deducted in calculating taxable income, the net-of-tax cost of borrowed funds is $(1-\tau) i$. The equilibrium condition that requires equating the nominal net returns on the marginal unit of capital to the net cost of funds therefore implies

$$
(1-\tau) f^{\prime}+(1-\tau \lambda) \pi=(1-\tau) i
$$

Before proceeding to discuss the housing sector, it is interesting to note that equation (2) implies

$$
i=f^{\prime}+\frac{1-\tau \lambda}{1-\tau} \pi
$$

In contrast to the traditional conclusion of Irving Fisher that the nominal interest rate rises point for point with the rate of inflation, equation (3) shows that, for a fixed real marginal product of capital, the rise in the interest rate reflects the tax deductibility of nominal interest and the mismeasurement of depreciation and inventory profits. With economic depreciation and no artificial inventory profits, $\lambda=0$ and $d i / d \pi=1 /(1-$ $\tau)$. With existing depreciation and inventory rules, $0<\lambda<1$ and $1<$ $d i / d \pi<1 /(1-\tau){ }^{12}$

If the individuals who provide capital to the business sector pay tax at rate $\theta$ on nominal interest income, the real net-of-tax interest that they earn is $(1-\theta) i-\pi$. From equation (3) it follows that

$$
(1-\theta)-\pi=(1-\theta) f^{\prime}+\frac{[\tau-\theta-(1-\theta) \tau \lambda]}{1-\tau} \pi
$$

The impact of inflation on the real net return to lenders depends on two things. First, $\tau-\theta$ reflects the difference between the advantage of deducting nominal interest payments at the corporate level and the disadvantage of paying tax on nominal interest income at the personal level. Second, $(1-\theta) \tau \lambda$ reflects the additional tax paid at the corporate level because of the mismeasurement of depreciation and inventory costs. For any marginal personal income tax rate greater than 30 percent, i.e. for $\theta>.30$, the coefficient of $\pi$ is negative..$^{13}$

11. See Auerbach (1978, appendix to chap. 4 above) for an explicit derivation of the relation between the true rate of depreciation and the increase in taxable income caused by historic cost depreciation. Feldstein ( $1980 d$, see chap. 11 below) discusses the additional contribution of FIFO inventory accounting. For the United States, a value of $\lambda=0.50$ is a reasonable approximation with the tax laws in effect in the late 1970s.

12. The expression is more complex when firms use equity as well as debt in marginal finance. It is important to emphasize that these expressions for $d i / d \pi$ are partial equilibrium relations that assume $f^{\prime}$ fixed.

13. The corporate tax rate $\tau$ is 0.46 and, as noted above, $\lambda$ has been estimated to be 0.50 (Feldstein, 1980d; see chap. 11 below). 


\subsubsection{The Housing Sector}

The owner-occupied housing sector uses capital but no labor to produce housing services. Since in the long-run capital can move freely between the two sectors, the equilibrium price of a unit of housing capital is the same as the price of a unit of business capital which in turn is the price of a unit of the general good. ${ }^{14}$ The price of housing services therefore depends on the cost of owning one unit of housing capital and of maintaining that capital.

More specifically, for each dollar of housing capital the individual pays or foregoes net interest of $(1-\theta) i^{15}$ Local property tax, maintenance, depreciation, and a standard risk premium add an additional net cost of $z$ per unit of housing capital.$^{16}$ Since the value of net housing capital rises at the rate of inflation, the real net cost of owning and maintaining a unit of housing capital is:

$$
r=(1-\theta) i+z-\pi
$$

Note that $r$ is thus the implicit rental cost of a unit of owner-occupied housing capital.

The demand for housing capital by individual homeowners reflects both the demand for housing services and the demand for housing capital as a portfolio asset. Since I have assumed that the amount of housing service is proportional to the housing stock it is not necessary to distinguish the demand for services from the demand for a portfolio asset. Instead, the demand for housing capital can be considered directly with its determinants reflecting both the portfolio and service characteristics. The simplest such specification is equation (6) where $h$ is the housing capital stock per employee and $\phi^{\prime}<0$. This equation implies that the relative demand for housing services and for other goods varies inversely with the implicit rental price of housing. ${ }^{17}$

14. By contrast, in the short run the stocks of housing capital and business capital are given and equilibrium must be achieved by changes in the prices of these capital stocks. See Poterba (1980) and Summers (1981).

15. This assumes that individuals borrow and lend at the same interest rate. It also reflects the U.S. tax rule that permits individuals to deduct mortgage interest payments in the calculation of taxable income.

16. I say "net" cost because local property taxes are a deductible expense in calculating individual taxable income. By "standard risk premium" I mean the premium for a "standard" or "basic" amount of housing capital; the risk premium may be a function of the amount of housing capital in a way specified below.

17. Since the other goods represent the numeralre, $r$ is also the rental price of housing relative to the price of other goods. A more general specification would make the demand for housing a function of real income and of wealth. Within the current paper, however, the equilibrium values of real income and wealth remain constant except for changes in the efficiency of resource allocation. If the initial condition of the economy is regarded as one of optimal resource allocation, the changes in resource allocation that result from a small increase in the rate of inflation do not change real income to a first-order approximation. A large change in inflation would, however, reduce real income. Similarly, a small increase in inflation would reduce real income if, in the initial condition, nonneutral tax rules cause 


$$
h=\phi(r)
$$

Even in the restricted form of equation (6), the demand for housing capital as an asset influences the form of the demand function, $\phi$. In particular, since each individual must own the housing capital that produces his housing services, an increase in the consumption of housing services beyond some level involves increasing portfolio risk. ${ }^{18}$ This implies that, for high values of $h$, the demand for housing capital is less responsive to the implicit rental price than would be true if individuals did not have to own their housing capital. ${ }^{19}$ Even when the implicit rental price would otherwise be zero or negative, risk considerations limit the demand for housing capital. ${ }^{20}$

\subsubsection{The Demand for Money}

Money plays two quite distinct roles in a model of equilibrium growth. First, the exogenously given rate of growth of the nominal money stock determines the rate of inflation. This follows directly from the fact that the stock of real money balances per employee must remain constant in equilibrium growth since real income per employee, real assets per employee, and the rate of interest are all constant. ${ }^{21}$ If real money balances per employee are to remain constant, the rate of growth of the nominal money stock $(\dot{M} / M)$ must equal the rate of growth of prices plus the rate of growth of the labor force:

$$
\frac{\dot{M}}{M}=\pi+n
$$

The second role of money is as an asset that absorbs savings and thereby reduces the equilibrium size of the real capital stock, $k+h$. As mentioned above, Tobin (1965) has emphasized that an increase in

there to be too much housing capital. A reduction in real income would cause individuals to consume less housing and this would partially offset the inflation-induced transfer of capital from the business sector to housing. Shifting one unit of capital from the business sector to housing reduces real income by the difference between the real marginal products of capital in the two sections and this income effect reduces the demand for housing capital by the marginal propensity to own housing capital as a function of real income. The real marginal product difference is less than $f^{\prime}$ which is approximatley 0.12 in the United States. The marginal housing-to-income ratio is less than three. Thus this real income effect offsets at most about one-third of any shift of capital from the business to housing sectors.

18. This is particularly true when the acquisition of housing capital is financed by borrowing.

19. The model assumes that all housing is owner-occupied when in reality about 75 percent of the housing capital stock is owner-occupied. The tax advantages and other aspects of home ownership probably outweigh risk considerations at most income levels. The tax advantage of homeownership is increased by inflation since rental property is adversely affected by historic cost depreciation rules.

20. This was probably the case in the $1970 \mathrm{~s}$.

21. If there is technical progress, the statement is true with "employee" interpreted as "effective employee." 
inflation, by increasing the real cost of holding money balances, encourages households to economize on real money balances and therefore to devote a larger share of their wealth to real capital formation. The importance of this substitution effect depends on the size of the stock of "outside money" (i.e., money that does not represent a liability of any private entity) relative to total wealth and on the elasticity of money demand with respect to the nominal rate of interest. The monetary base, a reasonable measure of the stock of outside money, ${ }^{22}$ was only $\$ 160$ billion in 1980 or less than 3 percent of the total stock of private wealth. Since all estimates of the interest elasticity of money demand are substantially less than one, it is clear that even major changes in the nominal rate of interest would have very little effect on the fraction of savings devoted to real capital formation. I shall therefore ignore the interest elasticity of demand completely and write the demand for real money balances per employee $(m)$ as a constant fraction $(\mu)$ of the corresponding real capital assets:

$$
m=\mu(k+h)
$$

\subsubsection{Public and Private Consumption}

The government consumes a fraction $(\gamma)$ of real national income and households consume a fraction $(1-\sigma)$ of real disposable income. National income consists of the output of the business sector plus the output of the owner-occupied housing sector ${ }^{23}$ To combine these two products, I assume a constant relative price of housing services, that is, an implicit rental of $\rho$ per unit of housing capital; national income per employee is thus $y+\rho h^{24}$ Real government spending per employee is

$$
g=\gamma(y+\rho h)
$$

Disposable income may be defined as national income minus both taxes paid $(t)$ and the loss in real money balances caused by inflation $(\pi m){ }^{25}$ Thus consumption per employee is

22. It would be wrong to include in the measure of outside money any interest-bearing government debt since the market interest rate would adjust with inflation. Tobin's procedure of combining money and government debt is therefore misleading; see Feldstein (1980c; chap. 5 above) for a model that distinguishes money, government debt, and private real capital.

23. This ignores the value of the services of the stock of money, an omission that has no qualitative effect on the results of this analysis.

24. The value of $\rho$ is the initial rental price of housing services. A small change in the rental price changes real income to the extent that $(a)$ it reallocates capital between $h$ and $k$ and $(b)$ the marginal product of business capital differs from $\rho$. That is, the change in real income is $f^{\prime} d k+\rho d h$. It would be incorrect to include a term of the form $h d r$ in evaluating the change in real income since $d r$ represents either a change in the implicit price that individuals pay themselves on housing or a change in the tax consequences of homeownership that would merely be offset by a change in other taxes.

25. Taxes include the taxes on capital income from corporations and industries and an additional nondistorting tax. Changes in tax revenue that result from changes in inflation are 


$$
c=(1-\sigma)(y+\rho h-t-\pi m)
$$

Since the government deficit equals the increase in the stock of money balances, that is $g-t=(\pi+n) m$, equation (10) can be rewritten:

$$
c=(1-\sigma)(y+\rho h-g+n m)
$$

This formulation, which is essentially due to Tobin (1965), assumes that households regard their increase in real balances as a component of disposable income even though the real resources available to households (i.e., the maximum feasible consumption) are only $y+\rho h-g{ }^{26}$ The amount that households save, including the amount that is saved in the form of increased real money balances, is therefore

$$
s=\sigma(y+\rho h-g+n m)
$$

or, using (9) to substitute for $g$,

$$
s=\sigma[(1-\gamma)(y+\rho h)+n m]
$$

\subsubsection{Growth Equilibrium}

Real savings per employee are divided into the increase of real business capital per employee $(\dot{K} / N)$, the increase of real housing capital per employee $(\dot{H} / N)$, and the increase of real money balances per employee $((\dot{M} / p) / N)$. Denoting total real wealth by $A$ and total real wealth per employee by $a$, we have

$$
\begin{aligned}
s=\frac{\dot{A}}{N} & =\frac{\dot{K}}{N}+\frac{\dot{H}}{N}+\frac{(\dot{M} / p)}{N} \\
& =\frac{\dot{K}}{K} k+\frac{\dot{H}}{H} h+\frac{(\dot{M} / p)}{M / p} m
\end{aligned}
$$

In steady-state equilibrium, all three stocks grow at the same rate as the population, implying that

$$
s=n a=n(k+h+m)
$$

Combining (13) and (15) gives the basic equation of growth equilibrium:

$$
\sigma[(1-\gamma)(y+\rho h)+n m]=n[k+h+m]
$$

Using (8) to substitute for $m,(6)$ to substitute for $h$, and (1) to substitute for $y$, equation (16) can be rewritten

$$
\sigma[(1-\gamma)(f+\rho \phi)+n \mu(k+\phi)]=n[k+\phi+\mu(k+\phi)]
$$

offset by changes in the nondistorting tax to keep total tax revenue unchanged. If the offsetting change in other sources of tax revenue were in a distortionary tax, the effect of inflation on real income would be more complex than the current analysis indicates. See Feldstein (1976, chap. 3 above) for a discussion of this issue.

26. Ignoring $n m$ in (11) or $\pi m$ in (10) would not change any of the qualitative results. 
Recall that $\phi$ is a function of $r$ and that equation (5) shows this implicit rental price to be $r=(1-\theta) i+z-\pi$. Equation (4) shows that the households' real net interest rate is given by $(1-\theta) i-\pi=(1-\theta) f^{\prime}+$ $x \pi$ where $x=[\tau-\theta-(1-\theta) \tau \lambda] /(1-\tau)$. Thus

$$
\phi=\phi\left[(1-\theta) f^{\prime}+x \pi+z\right]
$$

If (18) is used to substitute for $\phi$ in (17), it provides an equation that determines the stock of business capital as a function of the inflation rate and the tax rules.

\subsubsection{Disequilibrium Adjustments}

The next section uses equations (17) and (18) to examine the equilibrium effects of changes in the rate of inflation and the tax rules. The complex expressions that result are readily interpreted in terms of the disequilibrium adjustments of the capital stock. This permits determining the directions of equilibrium change without having to specify numerical values for individual parameters.

Two very plausible disequilibrium adjustment assumptions will be made. The first is labelled the "net adjustment assumption": an increase in either type of capital stock per employee above its equilibrium value causes total wealth per employee to decline:

$$
\frac{d \dot{a}}{d k}<0
$$

and

$$
\frac{d \dot{a}}{d h}<0
$$

Equation (19) is satisfied if, when $k$ exceeds its equilibrium value, $k$ falls and the other types of wealth (housing plus real money balances) do not increase by an even greater amount. A similar interpretation holds for equation (20).

The second assumption is labelled the "partial adjustment assumption": when the stock of business capital per employee exceeds its equilibrium value, the total wealth per employee will decline even if housing wealth per employee is held constant:

$$
\left.\frac{\partial \dot{a}}{\partial k}\right|_{h}<0
$$

Since the fall in $k$ is likely to raise the housing stock, holding housing constant should make it easier to satisfy the condition that a positive perturbation of $k$ causes total wealth to decline. In this sense, equation (21) is a weaker assumption than (19) and (20). 


\subsection{Effects of Changes in Inflation}

We are now in a position to examine the effect of inflation on the capital intensity of the business sector, on the consumption of housing services, and on the real net return to savers. Before beginning the formal derivations, it is useful to consider the general logic of the process.

A higher rate of inflation reduces the after-tax profitability of investment because the tax accounting procedures for dealing with depreciation and inventories raise the effective tax rate. This lower after-tax profitability means that firms can pay only a lower real net rate of return to the creditors who supply their capital.

The net return to the suppliers of business capital is also affected by the fact that firms deduct nominal interest payments and that lenders pay tax on nominal interest receipts. This matters, however, only to the extent that the tax rates of borrowers and lenders are different.

On balance, inflation lowers the real net rate of return and therefore reduces the implicit rental cost of housing. This in turn raises the consumption of housing services relative to the output of other goods. The present section will now show explicitly that this reduces the equilibrium amount of business capital per employee and therefore the productivity of the labor force. The decrease in productivity and the reallocation of production to housing also lowers the real income per capita. ${ }^{27}$

Substituting equation (18) into (17) and totally differentiating with respect to $k$ and $\pi$ yields:

$$
Q_{1} d k+Q_{2} \phi^{\prime} x d \pi=0
$$

and thus

$$
\frac{d k}{\mathrm{~d} \pi}=-\frac{Q_{2} \phi^{\prime} x}{Q_{1}}
$$

where the expressions for $Q_{1}$ and $Q_{2}$, derived in the appendix, are shown to satisfy $Q_{1}=d \dot{a} / d k$ and $Q_{2}=d \dot{a} / d h$. From equations (19) and (20) we have $Q_{1}<0$ and $Q_{2}<0$. Consequently, since $\phi^{\prime}<0$, the sign of $d k / d \pi$ is the same as the sign of $x=[\tau-\theta-(1-\theta) \tau \lambda] / 1-\tau$. As I noted above, with realistic values of $\lambda$ and $\tau, x<0$ for any $\theta>0.30$ and therefore $d k / d \pi$ $<0$.

Since a higher rate of inflation unambiguously reduces the real equilibrium capital intensity of the business sector, it increases the pretax real rate of return $\left(f^{\prime}\right)$. The net-of-tax real rate of return and the rental cost of housing nevertheless declines. To see this, note that since $(1-\theta) i-\pi=$ $(1-\theta) f^{\prime}+\pi x$,

27. Although the analysis takes the saving rate $(\sigma)$ as fixed, the reduction in the real net rate of return implies that the saving rate in a more general model would probably also be reduced, thereby further decreasing the capital intensity of production. 


$$
\begin{aligned}
\frac{d[(1-\theta) i-\pi]}{d \pi} & =\frac{d\left[(1-\theta) f^{\prime}+\pi x\right]}{d \pi} \\
& =(1-\theta) f^{\prime \prime} \frac{d k}{d \pi}+x
\end{aligned}
$$

Since $f^{\prime \prime}, d k / d \pi$, and $x$ are all negative, it seems at first as if the effect of inflation on the real net return is ambiguous. However, substituting (23) for $d k / d \pi$ yields

$$
\frac{d[(1-\theta) i-\pi]}{d \pi}=\left[Q_{1}-(1-\theta) f^{\prime \prime} \phi^{\prime} Q_{2}\right] x / Q_{1}
$$

Using the expressions for $Q_{1}$ and $Q_{2}$ in the appendix gives

$$
\frac{d[(1-\theta) i-\pi]}{d \pi}=\left[\sigma(1-\gamma) f^{\prime}+\sigma n \mu-n(1+\mu)\right] x / Q_{1}
$$

Since both $x$ and $Q_{1}$ are negative, the sign of $d[(1-\theta) i-\pi] / d \pi$ is the same as the sign of

$$
Q_{3}=\sigma(1-\gamma) f^{\prime}+\sigma n \mu-n(1+\mu) .
$$

The appendix shows that $Q_{3}=\partial \dot{a} / \partial k \mid h$. The partial adjustment assumption implies $Q_{3}<0$ and therefore, from equation (26) $d[(1-\theta) i-\pi] /$ $d \pi<0.28$

Since the demand for housing is a function of the real interest rate, an increase in inflation unambiguously increases the equilibrium stock of housing capital: ${ }^{29}$

$$
\begin{aligned}
\frac{d h}{d \pi} & =\phi^{\prime} \frac{d r}{d \pi} \\
& =\phi^{\prime} \frac{d[(1-\theta) i-\pi+z]}{d \pi} \\
& =\frac{\phi^{\prime} Q_{3} x}{Q_{1}}>0
\end{aligned}
$$

Since all four terms are negative, $d h / d \pi>0$.

28. An alternative suggested by Pentti Kouri is a model in which saving is optimized in a Ramsey model by invididuals who live forever. In this case, the real net rate of return, $(1-$ $\theta) i-\pi$, is fixed. This in turn means that $r$ and therefore $h$ are not influenced by inflation. It follows, however, from equation (4) that $f^{\prime}$ must rise to keep the right-hand side constant; since $f^{\prime \prime}<0, d k / d \pi<0$. In words, to earn the same real net return when inflation raises the effective tax rate, the pretax return would have to increase and therefore the business capital stock would have to decrease.

29. Note again that, to the extent that housing is also a function of real income and real income declines, this will partially of fset the value of $d h / d \pi$ derived in equation (28). 
The final effect of inflation that I wish to examine is on total real income, $y+\rho h$. If the initial allocation of capital between business and housing were optimal, a small increase in inflation would leave real income unchanged; since any small change from an optimum involves no loss to a first order approximation. But if taxes and inflation make the initial condition suboptimal, the reallocation of capital caused by an increase in inflation will have a first-order effect on real income. More specifically, the very favorable tax treatment of owner-occupied housing implies that even in the absence of inflation the real return to marginal housing capital $(\rho)$ is less than the return to business capital $\left(f^{\prime}\right)$. A positive inflation rate widens the gap. This implies that a reallocation of capital from the business sector causes a loss of real income. More formally the change in real income induced by an inflation-induced change in the allocation of capital is

$$
\frac{d(y+\rho h)}{d \pi}=f^{\prime} \frac{d k}{d \pi}+\rho \frac{d h}{d \pi}
$$

Substituting from (23) and (28) implies

$$
\frac{d(y+\rho h)}{d \pi}=\left(\rho Q_{3}-f^{\prime} Q_{2}\right) \frac{\phi^{\prime} x}{Q_{1}}
$$

Substituting for $Q_{2}$ and $Q_{3}$ from the appendix yields,

$$
\begin{aligned}
\frac{d(y+\rho h)}{d \pi}= & {\left[\rho\left(\sigma(1-\gamma) f^{\prime}+\sigma n \mu-n(1+\mu)\right)\right.} \\
& -f^{\prime}(\sigma(1-\gamma) \rho+\sigma n \mu \\
& -n(1+\mu))] \phi^{\prime} x / Q_{1} \\
& =\left(f^{\prime}-\rho\right) n[1+(1-\sigma) \mu] \phi^{\prime} x / Q_{1}
\end{aligned}
$$

Thus with $f^{\prime}>\rho$, real income falls since $\phi^{\prime}<0, x<0$ and $Q_{1}<0$.

\subsection{Indexing the Tax Rules}

Inflation causes a misallocation of capital between the business and housing sectors because the tax laws mismeasure capital income and expenses. A complete indexing of the tax laws would eliminate this source of the distortion caused by inflation. Complete indexing has three aspects: (1) eliminating the mismeasurement of depreciation and inventory profits that causes business operating profits to be overstated; (2) limiting the deductions for business interest to real interest payments only; and (3) limiting the taxation of household interest income and expenses to the real interest rate. This section shows the neutrality of 
inflation when all three of the features are present and examines nonneutrality when there is only partial indexing. ${ }^{30}$

Consider a general tax-indexing rule under which firms pay tax at rate $\tau_{1}$ on operating profits net of real interest expenses but deduct the inflation component against their tax liability at rate $\tau_{2}$; under existing law $\tau_{1}=\tau_{2}$ while with complete indexing $\tau_{2}=0$. With these rules, the firms' equilibrium condition (analogous to equation 2 ) is

$$
\left(1-\tau_{1}\right) f^{\prime}+\left(1-\tau_{1} \lambda\right) \pi=i-\tau_{1}(i-\pi)-\tau_{2} \pi
$$

If households are taxed on real interest receipts at rate $\theta_{1}$ and on the inflation component of interest payments at rate $\theta_{2}$, the real net rate of interest is $i-\theta_{1}(i-\pi)-\theta_{2} \pi-\pi=\left(1-\theta_{1}\right) i+\left(\theta_{1}-\theta_{2}\right) \pi-\pi$. Since the implicit rental cost of housing is the real net rate of interest plus the "other costs per unit of housing capital" $(\mathrm{z})$, the rental cost of housing is

$$
r=\left(1-\theta_{1}\right) i+\left(\theta_{1}-\theta_{2}\right) \pi-\pi+z
$$

and, using (32) to eliminate $i$,

$$
\begin{aligned}
r=\left(1-\theta_{1}\right) f^{\prime} & +\frac{1-\theta_{1}}{1-\tau_{1}}\left(1-\tau_{1} \lambda\right) \pi-\frac{1-\theta_{1}}{1-\tau_{1}}\left(\tau_{1}-\tau_{2}\right) \pi \\
& +\left(\theta_{1}-\theta_{2}\right) \pi-\pi+z
\end{aligned}
$$

When there is no indexing $\left(\tau_{1}=\tau_{2}\right.$ and $\left.\theta_{1}=\theta_{2}\right)$, equation (34) reduces to the same implicit rental cost that has already been analyzed. With complete indexing $\left(\theta_{2}=\tau_{2}=\lambda=0\right)$, equation (34) reduces to

$$
r=\left(1-\theta_{1}\right) f^{\prime}+z
$$

Here the implicit rental price is independent of inflation..$^{31}$

It is sometimes proposed that the elimination of historic cost depreciation be coupled with limiting the business interest deduction to the real cost of funds. In terms of equation (34), this implies $\lambda=\tau_{2}=0$ but $\theta_{1}=$ $\theta_{2}$. The resulting implicit rental cost of housing is then:

$$
\begin{aligned}
& r=(1-\theta) f^{\prime}+z+\left[\frac{1-\theta}{1-\tau_{1}}-\frac{1-\theta}{1-\tau_{1}} \tau_{1}-1\right] \pi \\
& r=(1-\theta) f^{\prime}+z-\left(1-\tau_{1}\right) \theta \pi
\end{aligned}
$$

30. These three forms of indexing are discussed in Feldstein, Green, and Sheshinski (1978, chap. 4 above), but there is no housing sector in that model and all of the distortions are in financial returns.

31. The allocation of capital still favors housing because the net services of housing are not taxed while interest income is taxable and the mortgage interest payments are deductible $\left(\theta_{1}>0\right)$, but this is a separate matter. 
An increase in inflation reduces the implicit rental cost because the firm is denied a deduction for the inflation premium in the interest rate but the household pays tax on that premium. An increase in the rate of inflation thus reduces the real net return to households on business capital and thereby lowers the cost of funds that enters the housing rental cost. Thus a partial indexing approach that focuses only on the firm may exacerbate the bias in favor of housing that is caused by inflation and clearly does not leave an inflation-neutral allocation of capital. More specifically, comparing (36) with (18) shows that the partial indexing rule causes a lower value of $r$ than the existing unindexed tax law if $\left(1-\tau_{1}\right) \theta>-x$; with $\tau=0.46$ and $\lambda=0.5$, this is satisfied for all values of $\theta<0.48 .^{32}$

Most countries have dealt with inflation by accelerating the rate of depreciation used for calculating taxable profits but without changing the tax treatment of interest income and expenses. Accelerating depreciation has two distinct effects. First, at any rate of inflation (including zero), this lowers the effective tax rate on operating profits. In the notation of equation (32), it is equivalent to increasing $f^{\prime}$; note that it is not equivalent to lowering $\tau_{1}$ since that would also affect the tax treatment of interest. Second, more rapid depreciation reduces the sensitivity of the tax to the rate of inflation, i.e., it lowers $\lambda$. To see the effects of these changes on the implicit rental cost of housing, set $\tau_{2}=\tau_{1}$ and $\theta_{2}=\theta_{1}$ in equation (34) and evaluate the total differential of $r$ with respect to $f^{\prime}$ and $\lambda$ :

$$
d r=(1-\theta) d f^{\prime}-\frac{(1-\theta)}{(1-\tau)} \tau \pi d \lambda
$$

The decrease in $\lambda$ raises the implicit rental cost of housing since it reduces the excess tax on business capital caused by historic cost accounting methods. Similarly the rise in $f^{\prime}$ raises the return on business investment and thus directly increases the implicit rental cost of owneroccupied housing. Although full indexing avoids all of the tax-induced distortions associated with inflation, any specific acceleration of depreciation can achieve the same effect only for one particular rate of inflation.

\subsection{Conclusion}

It is ironic that an easy money policy aimed at stimulating investment in plant and equipment is likely to have just the opposite effect: reducing the long-run capital intensity of production. Whatever the short-run virtue of expansionary policies, the long-run consequence of inflation under existing U.S. tax laws is to reduce investors' demand for business capital and to increase it for owner-occupied housing.

32. Note that correcting the depreciation and inventory rules (i.e., making $\lambda=0$ ) is sufficient to achieve inflation neutrality if $\tau=\theta$. 
The simple model developed in this paper shows more generally how the expectation of further inflation of the sort that resulted from the inflationary experience of the $1960 \mathrm{~s}$ and $1970 \mathrm{~s}$ can have very substantial effects on the real economy. The notion that a fully anticipated monetary expansion or inflation has no effect on the real economy is not plausible in a modern economy with a complex set of tax rules. The specific effect of inflation will, moreover, vary from country to country and from time to time as a function of the particular features of the country's fiscal structure.

It would be useful to extend the current analysis in a variety of ways. Of particular interest would be replacing the debt-only assumption of corporate finance with a mixture of debt and equity. This would bring out the more limited significance of the corporate deductibility of nominal interest payments and would show the relevance of the taxation of nominal capital gains. A further (or alternative) extension to include interestbearing government debt as well as money would permit the government to vary the real interest rate through its debt management policy and would show the effect of inflation on residential investment when low-risk government debt is an alternative asset. Finally, since the analysis here is limited to U.S. tax rules, it would be quite interesting to see it altered to describe the tax rules of other countries and used to analyze the effect of inflation in these settings.

The present model, either in its current form or with the extensions described above, could be the basis for a more explicit dynamic analysis of the transition path when the expected rate of inflation changes. This in turn would provide a sounder foundation for the empirical analysis of the effect of inflation on the accumulation of residential and nonresidential capital.

\subsection{Appendix}

This appendix discusses the relation of $Q_{1}, Q_{2}$, and $Q_{3}$ of section 6.2 to the disequilibrium adjustment process.

Combining equations (13) and (14) yields

$$
\sigma[(1-\gamma)(\mathrm{y}+\rho h)+n m]=\frac{\dot{A}}{N}
$$

It follows directly from differentiating $a$ with respect to time that

$$
\frac{\dot{A}}{N}=\dot{a}+n a
$$

Thus (38) can be rewritten

$$
\sigma[(1-\gamma)(y+\rho h)+n m]=n a+\dot{a}
$$


Along a balanced growth path, $\dot{a}=\dot{k}=\dot{h}=\dot{m}=0$. This condition was imposed for the analysis in the text. But when $k, h$ or $m$ are not at their equilibrium values, these ratios will change to bring about equilibrium.

By substituting $h=\phi$ and $m=\mu(k+h)$, equation (40) can be rewritten:

$$
\sigma[(1-\gamma)(f+\rho \phi)+n \mu(k+\phi)]-n(1+\mu)(k+\phi)=\dot{a}
$$

Taking the derivative of both sides with respect to $k$ yields:

$$
\begin{aligned}
& Q_{1}=\sigma(1-\gamma) f^{\prime}+\sigma n \mu-n(1+\mu) \\
& +(\sigma[(1-\gamma) \rho+n \mu]-n(1+\mu)) \phi^{\prime}(1-\theta) f^{\prime \prime} \\
& =d \dot{a} / d k .
\end{aligned}
$$

Similarly the derivative of (41) with respect to $h$ yields

$$
Q_{2}=\sigma[(1-\gamma) \rho+n \mu]-n(1+\mu)=d \dot{a} / d h
$$

The net adjustment assumptions (19 and 20) imply directly that $Q_{1}<0$ and $Q_{2}<0$.

To derive the interpretation of $Q_{3}$ of equation (27), take the partial derivative of both sides of equation (41) with respect to $k$ holding $h$ (i.e., $\phi)$ constant:

$$
Q_{3}=\sigma\left[(1-\gamma) f^{\prime}+n \mu-n(1+\mu)\right]=\left.\frac{\partial \dot{a}}{\partial k}\right|_{h}
$$


II

\section{Inflation and \\ Effective \\ Tax Rates}


